\title{
The 2015 Dutch Food-Based Dietary Guidelines on Alcohol Consumption - A Critical Review
}

\author{
Hendriks $\mathrm{HFJ}^{*}{ }^{1}$, Stockley $\mathrm{CS}^{2}$ and Calame $\mathrm{W}^{3}$
}

${ }^{1}$ Hendriks Nutrition Support for Business, Zeist, Netherlands

${ }^{2}$ The Australian Wine Research Institute, Urrbrae, South Australia, Australia

${ }^{3}$ Statistical BV, Wassenaar, Netherlands

${ }^{*}$ Corresponding author: Hendriks HFJ, Hendriks Nutrition Support for Business, Laan van Cattenbroeck 70, 3703BP Zeist, Netherlands, Tel: +31651010454, E-mail: henk.hendriks5@gmail.com

Citation: Hendriks HFJ, Stockley CS, Calame W (2018) The 2015 Dutch Food-Based Dietary Guidelines on Alcohol Consumption - A Critical Review. J Nutr Health Sci 5(3): 302. doi: 10.15744/2393-9060.5.302

Received Date: April 10, 2018 Accepted Date: September 11, 2018 Published Date: September 13, 2018

\begin{abstract}
Background: Recently the Dutch Health Council has issued a revised alcohol guideline stating: Do not drink alcohol, or if any only drink one glass daily. The current guidelines are intended to obtain the lowest disease burden of the most burdensome diseases in The Netherlands. The current paper aims to estimate the overall impact of alcohol consumption on these diseases.

Methods: The meta-analyses selected by the Council were used to estimate the association between alcohol consumption and overall disease risk. The risk association was estimated by totaling all available separate associations. Similarly, incidences numbers and Disability-Adjusted Life Years (DALY's) were calculated.

Results: Data show that the cumulative risk is lowest for the alcohol consumption categories $2.5-14.9 \mathrm{~g}$ alcohol/day and the category 15 to $29.9 \mathrm{~g}$ alcohol/day. Also, the lowest number of diseases incidence and the lowest disease burden were observed in these drinking categories for both Dutch men and women.

Conclusion: This paper suggests that moderate alcohol consumption of up to $30 \mathrm{~g}$ of alcohol per day is associated with the lowest risk for the most burdensome diseases in the Netherlands for both men and women.

Key words: Alcohol; Moderate Drinking; Disease Incidence; DALY's

List of abbreviations: DALY: Disability-Adjusted Life Years; g: gram; COPD: Chronic Obstructive Pulmonary Disease; HDL: High density lipoprotein; LDL: Low density lipoprotein; YLL: Years of Life Lost; YLD: Years Lost due to Disability; STIVA: Dutch acronym for Foundation for Responsible Alcohol Consumption; RR: Relative Risk; CHD: Coronary Heart Disease
\end{abstract}

\section{Introduction}

Alcohol misuse is amongst the main health concerns of our time and represents a significant disease burden and associated economic burden $[1,2]$. It contributes to overall morbidity and mortality by increasing the risk for certain cancers, certain cardiovascular diseases, infectious diseases, injuries, neuropsychiatric diseases, as well as other diseases and disorders [1]. 'Heavy', 'binge' and 'underage' alcohol consumption all contribute to the disease burden attributed to alcohol $[3,4]$. Alcohol consumed in moderation, however, has been documented to be associated with lower total mortality mainly because moderate consumption is associated with reduced coronary heart disease mortality, reduced incidence of type 2 diabetes and, potentially, reduced cognitive decline and incidence of dementia [5-9].

There are, however, considerable differences between national alcohol drinking guidelines. This variation is interesting since the epidemiological research underlying the relationships between alcohol consumption and health outcomes, such as coronary heart disease, tends to be consistent as is the definition for 'moderate' consumption in the scientific literature [10]. This definition is based on a level above which the risk of all-cause mortality increases and is approximately $20 \mathrm{~g}$ alcohol/day for both men and women. Guidelines vary in the actual amount of alcohol recommended, the role of gender, drinking pattern and drinking frequency, and the presence or absence of recommendations on abstinence days. The interpretation of the scientific literature may vary because the aim and strategy for guideline development differs between countries [11]. Recently, the Dutch Health Council issued new dietary guidelines that consider alcohol consumption [12,13]. Alcohol consumption in The Netherlands is estimated at about 10 liters of pure alcohol per capita per year (age 15+) and slightly but steadily decreasing over the last decades. 
Development of the current 2015 Dutch dietary guidelines followed a strategy that differed from that of the previous version issued in 2006 [14]. The older drinking guidelines assumed that any level of alcohol consumption associated with an overall health benefit was acceptable. The current drinking guidelines, however, were based on an intention to prevent disease and optimize health through an optimal diet and dietary habits. Optimal health was defined as the lowest incidence, and therefore, the lowest expected disease burden of the ten most burdensome diseases in The Netherlands. These ten diseases included: coronary heart disease, stroke, heart failure, diabetes mellitus type 2, lung diseases (COPD), breast cancer, colorectal cancer, lung cancer, dementia and depression.

The main change has been a reduction in the upper limit for daily alcohol consumption. The 2006 guideline was 'When you consume alcohol, drink in moderation', which may correspond to on average of up to two glasses per day for men and on average of up to one glass per day for women. The current recommendation for both men and women, however, is 'Do not drink alcohol or if any do not drink more than one glass daily" [13,14]. The Dutch Health Council considers that drinking more than one glass daily does not further increase the health benefit associated with moderate alcohol consumption as demonstrated by the absence of a further decrease in the overall mortality curve [5].

The current paper aims to estimate the overall impact of alcohol consumption on the ten most burdensome diseases in The Netherlands, by pooling the risks and benefits associated with alcohol consumption for those diseases using studies selected by the Dutch Health Council itself. In this way, we attempt to estimate the overall health effect that may be expected when drinking in moderation. The outcome of this estimation is compared to the current recommendation formulated by the Council.

\section{Methods}

\section{Dutch Food-based Dietary Guidelines}

Development and formulation of the Dutch dietary guidelines 2015 have been previously described [12]. In short, a multidisciplinary team evaluated the peer-reviewed literature on the relationship between alcohol consumption as well as the consumption of the three main alcoholic beverages - beer, wine and spirits - and the risk of acquiring the ten most burdensome diseases in The Netherlands $[15,16]$. These ten diet-related chronic diseases in The Netherlands are coronary heart disease, stroke, heart failure, type 2 diabetes, chronic obstructive pulmonary disease, breast cancer, colorectal cancer, lung cancer, dementia and depression. The overall aim of the Council was to provide a science-based guideline that focused on preventing these ten currently most burdensome diseases in The Netherlands.

The state-of-the-art of the science was described in two background documents, one on 'alcohol' and one on 'beer, wine and distilled spirits' $[17,18]$. The latter background document was published, because the guidelines were to be formulated with the consumer in mind: guidelines were to be given on foods or food products rather than on nutrients or ingredients, such as alcohol. The focus was on meta-analyses as well as pooled analyses studies and systematic reviews in peer-reviewed journals up to July 2014.

Judgments were made on the totality of evidence, that is, were based on both experimental as well as observational data. Findings were categorized as 'strong' or 'weak evidence', 'inconsistent effects', 'too little evidence' or 'effect unlikely' for experimental and observational data separately. Next, the team selected only findings with a strong level of evidence for deriving the guidelines. Convincing evidence was based on strong evidence from the experimental data either in or not in combination with strong evidence from prospective cohort studies. Plausible evidence was based on strong evidence from prospective cohort studies only.

Intervention studies were only considered in the advice when several preset criteria were met. One criterion concerned the biomarkers used for evaluation. The only biomarkers accepted by the team were blood pressure, LDL-cholesterol and body weight. This means that virtually no intervention studies were considered for moderate alcohol consumption, because most physiological effects of moderate alcohol consumption on metabolic disease risk factors do not concern blood pressure, LDL-cholesterol and body weight. Rather, moderate alcohol consumption appears to act through other mechanisms, such as an increase in HDL cholesterol, a decrease in fibrinogen and improved glucose homeostasis [19-25].

Disease incidences were derived from the open National database with information on diseases incidence in the Netherlands [26]. The incidence of the most burdensome diseases was only known for nine out of the ten selected diseases as depression was not registered separately. Disease registration listed 'mood disorders', of which depression is a major contributor [27]. Also, the association between alcohol consumption and disease incidence/relative risk has not been summarized in meta-analyses, pooled analyses and systematic reviews of sufficient quality for depression and lung diseases (COPD) and, therefore, these had to be excluded from the presented estimates.

\section{Methodological Approach}

In the paper presented here, the meta-analyses selected by the Council were used to estimate the association between alcohol consumption and overall disease risk. The risk association was estimated by totaling all available separate associations corrected for their relative contribution to the disease burden in the Dutch population. Incidence correction was performed by multiplying the relative risk described for a specific disease risk in a specific drinking category with the relative incidence of that disease in the population. Gender specificity was accounted for using both the gender-specific alcohol related associations and the gender- 
specific disease incidences.

Similarly, and in addition to what the Council has estimated, absolute numbers of incidences were calculated in an attempt to estimate the number of disease incidences prevented or increased by alcohol consumption. Moreover, to account for the severity of the respective diseases, a calculation was performed applying Disability-Adjusted Life Years (DALY's). These DALY's consist of years of life lost to premature mortality due to the disease (YLL) and years lived with the disability itself (YLD). This information was based on information from 2011 and expressed as DALY's life years [28].

\section{Alcohol Drinking Categories}

Studies are usually reported in grams of alcohol. Alcohol drinking categories were subdivided as was done for the guideline, viz. a non-drinking/rare drinking control category of 0-2.5 g alcohol/day, 2.5-14.9 g alcohol/day, 15-29.9 g alcohol/day, 30-60 g alcohol/ day and more than $60 \mathrm{~g}$ alcohol/day. For translation into common practice, a standard glass of alcoholic beverage was defined as $250 \mathrm{ml}$ of beer, $100 \mathrm{ml}$ of wine and $35 \mathrm{ml}$ of spirits. This means that each standard glass of alcoholic beverage contains about $10 \mathrm{~g}$ of alcohol, which is the Dutch measure of a standard drink [17]. The guideline that was formulated based on this evidence was: "... do not drink more than one glass daily", that is, $10 \mathrm{~g}$ alcohol/day.

\section{Results}

The incidence of the nine most burdensome diseases in The Netherlands is provided in Table 1 . The incidence differs substantially for some diseases between men and women. Breast cancer occurs with a high incidence (13,990 in 2011) in Dutch women, which is not the case for Dutch men (80 in 2011).

\begin{tabular}{|c|c|c|c|c|c|}
\hline Disease & $\begin{array}{c}\text { Number of } \\
\text { cases }\end{array}$ & $\begin{array}{c}\text { Number of } \\
\text { men }\end{array}$ & $\begin{array}{c}\text { Percentage } \\
\text { of men }\end{array}$ & $\begin{array}{c}\text { Number of } \\
\text { women }\end{array}$ & $\begin{array}{c}\text { Percentage } \\
\text { of women }\end{array}$ \\
\hline Coronary heart disease & 48,880 & 27,580 & 56.4 & 21,300 & 43.6 \\
\hline Stroke & 26,200 & 13,050 & 49.8 & 13,150 & 50.2 \\
\hline Heart failure & 26,580 & 11,150 & 41.9 & 15,430 & 58.1 \\
\hline Diabetes mellitus type 2 & 52,740 & 28,890 & 54.8 & 23,850 & 45.2 \\
\hline Lung diseases (COPD) & 32,500 & 17,250 & 53.1 & 15,250 & 46.9 \\
\hline Breast cancer & 14,070 & 80 & 0.6 & 13,990 & 99.4 \\
\hline Colorectal cancer & 13,260 & 7,200 & 54.3 & 6,060 & 45.7 \\
\hline Lung cancer & 11,670 & 7,100 & 60.8 & 4,570 & 39.2 \\
\hline Dementia & 12,650 & 4,070 & 32.2 & 8,580 & 67.8 \\
\hline Total & 238,550 & 116,370 & 48.8 & 122,180 & 51.2 \\
\hline
\end{tabular}

*These numbers were obtained from www.volksgezondheidenzorg.info/ranglijst-ziekten-op-basisvan-ziekten and concern data obtained for 2011. Depression was not separately ascertained; in 2011, 280,000 persons were diagnosed with mood disorders, of which depression was most common. Table 1: Incidence of the nine most burdensome diseases in the Dutch population in both men and women*

The associations between alcohol consumption and the most burdensome diseases are summarized in Table 2. The associations have been described in studies referred to in the Table 2. CHD, stroke, heart failure, diabetes type 2 and dementia all have a

\begin{tabular}{|c|c|c|c|c|c|c|c|c|c|c|}
\hline & \multicolumn{5}{|c|}{ Relative Risk for Men } \\
\hline
\end{tabular}

${ }^{*}$ Gender specific relative risks were derived from the publications referred to for each specific disease. ${ }^{\wedge}$ Risks have been provided in two decimals. " The relative risk for the category $>60 \mathrm{~g}$ alcohol /day were assumed to be similar as the $>30 \mathrm{~g}$ alcohol/day category, because the relevant meta-analysis did only provide a relative risk for $>30 \mathrm{~g}$ alcohol/day. ${ }^{13} \mathrm{The} \mathrm{RR}$ is not presented, this is an estimate. ${ }^{9}$ Anstey indicates that the RR does not exceed 1 at very high consumption levels, this figure represents an average RR for dementia, Alzheimer's disease and vascular dementia.

Table 2: Relative risks for the most burdensome diseases in Dutch men and women per alcohol consumption category^ 
J-shaped association with alcohol consumption in both genders, whereas overall the cancers show a tendency to an increased relative risk. Gender influences both disease incidence and the observed associations between alcohol consumption and certain diseases. Therefore, the associations between disease and alcohol consumption are shown for men and women separately.

Subsequently, the relative contributions per disease and per drinking category were calculated and are provided in Figure $1 \mathrm{~B}$ and $1 \mathrm{C}$ for men and women, respectively. The relative risks associated with alcohol consumption for men and women were multiplied by the contribution of each of the eight diseases to the total, based on the incidence of the disease in the Dutch population. These risk contributions were then added up providing a theoretical total representing the total relative risk attributed to the eight most burdensome diseases in The Netherlands as a function of alcohol consumption (Figure 1A).
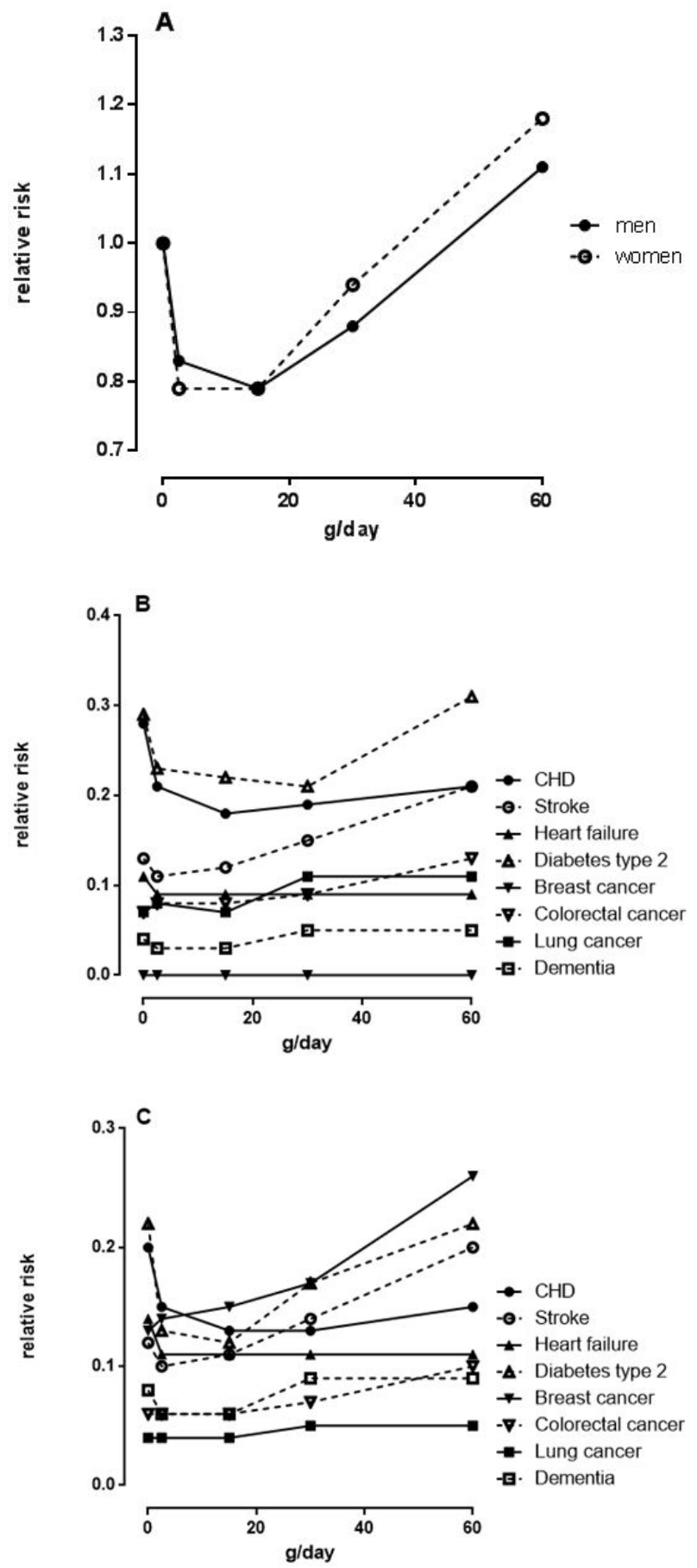

Alcohol consumption categories are: 0 g/day: 0-2.5; $2.5 \mathrm{~g} /$ day: $2.5-14.9 ; 15 \mathrm{~g} /$ day: 15-29.9; $30 \mathrm{~g} /$ day: 30-59.9; $60 \mathrm{~g} /$ day or higher: $\geq 60$. The lowest alcohol consumption level of each alcohol consumption category has been used on the $\mathrm{X}$-axis to indicate the alcohol consumption category. Risks were calculated for the whole population corrected for the gender ratio in the Dutch population.

Figure 1: Cumulative relative risks for the most burdensome diseases in the Netherlands per alcohol consumption category for men and women (A), relative risks for the most burdensome diseases in men (B) and relative risks for the most burdensome diseases in women (C) 
These total relative risks for men and women are illustrated in Figure 1A. In addition, the relation for the total Dutch population per disease was calculated for by adding up men and women corrected for the gender ratio in the Dutch population (Figures $1 \mathrm{~B}$ and $1 \mathrm{C})$. Figure 1 shows that the cumulative risk is lower for the alcohol consumption categories $2.5-14.9 \mathrm{~g}$ alcohol/day and the category 15 to $29.9 \mathrm{~g}$ alcohol/day as compared to the control group of people drinking $0-2.5 \mathrm{~g}$ alcohol/day. The Figure $1 \mathrm{~A}$ effectively highlights that there is a J-shaped relationship between alcohol consumption and cumulative relative risk for Dutch men and women, where risk of disease is lower for drinking more moderate amounts of alcohol compared with both the control group and heavier consumption.

In both men and women, the cumulative risk for the category 30-60 $\mathrm{g}$ alcohol/day is higher as compared to the two lower alcohol consumption categories (2.5-14.9 and 15-29.9 g alcohol/day), but somewhat lower as compared to the control, non-drinking/rare drinking control category. The category of those drinking on average more than $60 \mathrm{~g}$ of alcohol/day have the highest cumulative risk for the eight most burdensome diseases in The Netherlands of all groups.

In addition, diseases incidence as a function of alcohol consumption was calculated. Data are shown in Table 3 . Distribution of total diseases incidence is very similar to the cumulative relative risk distribution with a difference in the nadir of the distribution. The cumulative relative risk was the same for women in the 2.5-14.9 and 15-29.9 $\mathrm{g}$ alcohol/d drinking group, whereas the diseases incidence was lowest in the 15-29.9 $\mathrm{g}$ alcohol/d drinking group for men.

\begin{tabular}{|c|c|c|c|c|c|c|c|c|c|c|}
\hline & \multicolumn{5}{|c|}{ Disease incidence for men } & \multicolumn{5}{c|}{ Disease incidence for women } \\
\hline Alcohol (g/day) & $\mathbf{0 - 2 . 5}$ & $\mathbf{2 . 5 - 1 4 . 9}$ & $\mathbf{1 5 - 2 9 . 9}$ & $\mathbf{3 0 - 6 0}$ & $\mathbf{7 6 0}$ & $\mathbf{0 - 2 . 5}$ & $\mathbf{2 . 5 - 1 4 . 9}$ & $\mathbf{1 5 - 2 9 . 9}$ & $\mathbf{3 0 - 6 0}$ & $>\mathbf{6 0}$ \\
\hline Disease & & & & & & & & & & \\
\hline CHD & 7,182 & 5,387 & 4,740 & 4,812 & 5,459 & 5,547 & 4,160 & 3,661 & 3,716 & 4,216 \\
\hline Stroke & 2,377 & 1,902 & 2,187 & 2,734 & 3,851 & 2,395 & 1,916 & 2,204 & 2,755 & 3,880 \\
\hline Heart failure & 2,706 & 2,165 & 2,111 & 2,084 & 2,084 & 3,745 & 2,996 & 2,921 & 2,884 & 2,884 \\
\hline Diabetes type 2 & 6,688 & 5,350 & 5,016 & 4,748 & 7,089 & 6,084 & 3,590 & 3,346 & 4,746 & 6,084 \\
\hline Breast cancer & 16 & 16 & 16 & 16 & 16 & 2,136 & 2,349 & 2,456 & 2,777 & 4,272 \\
\hline Colorectal cancer & 1,169 & 1,227 & 1,227 & 1,461 & 2,116 & 984 & 1,033 & 1,033 & 1,230 & 1,781 \\
\hline Lung cancer & 1,154 & 1,362 & 1,166 & 1,709 & 1,709 & 921 & 774 & 921 & 977 & 977 \\
\hline Dementia & 866 & 641 & 641 & 961 & 961 & 1,826 & 1,351 & 1,351 & 2,026 & 2,026 \\
\hline Total & 22,158 & 18,050 & 17,104 & 18,525 & 23,283 & 23,638 & 18,169 & 17,894 & 21,110 & 26,119 \\
\hline
\end{tabular}

"Incidences has been expressed as absolute numbers. Disease incidence distribution was calculated from diseases incidence (Table1) and relative risks for the most burdensome diseases in Dutch men and women per alcohol consumption category (Table 2).

Table 3: Diseases incidence distribution for men and women for the most burdensome diseases in The Netherlands per alcohol consumption category"

Burden of disease differs per disease and, therefore, the disability adjusted life years (DALYs) were also calculated for each drinking group for both men and women and for the total Dutch population per disease for men and women (Figure 2A,2B and 2C). Again, drinking in moderation reduced DALYs with the lowest disease burden in that drinking 15-29.9 $\mathrm{g}$ alcohol/day for both men and women in the Netherlands.

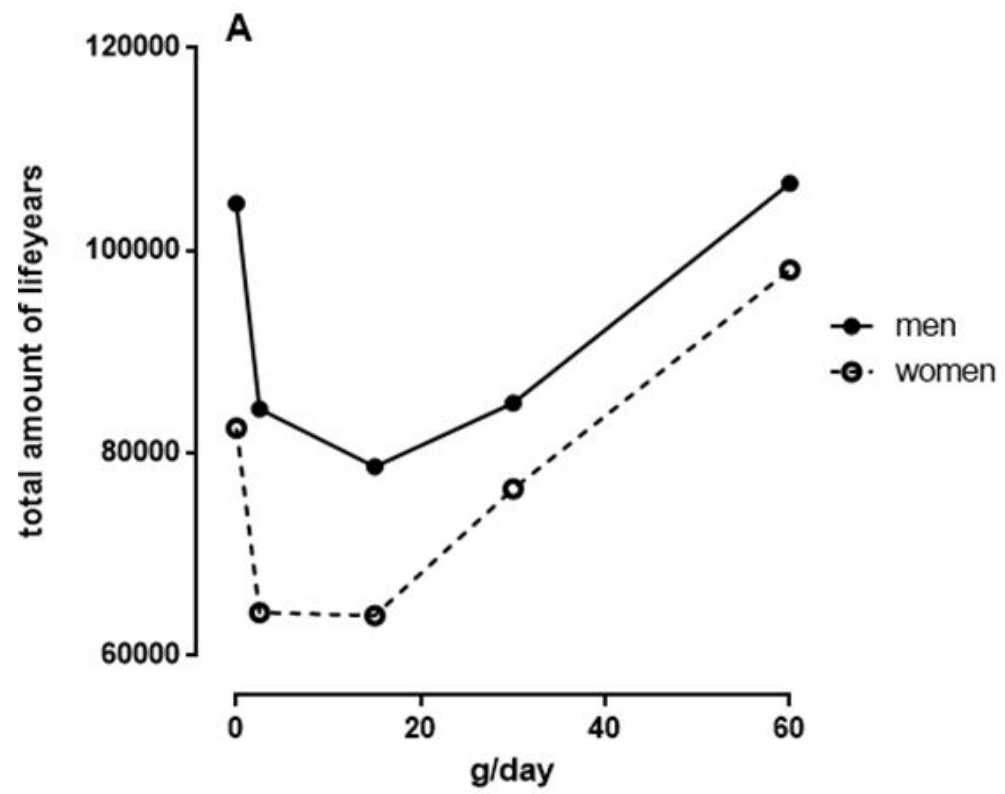



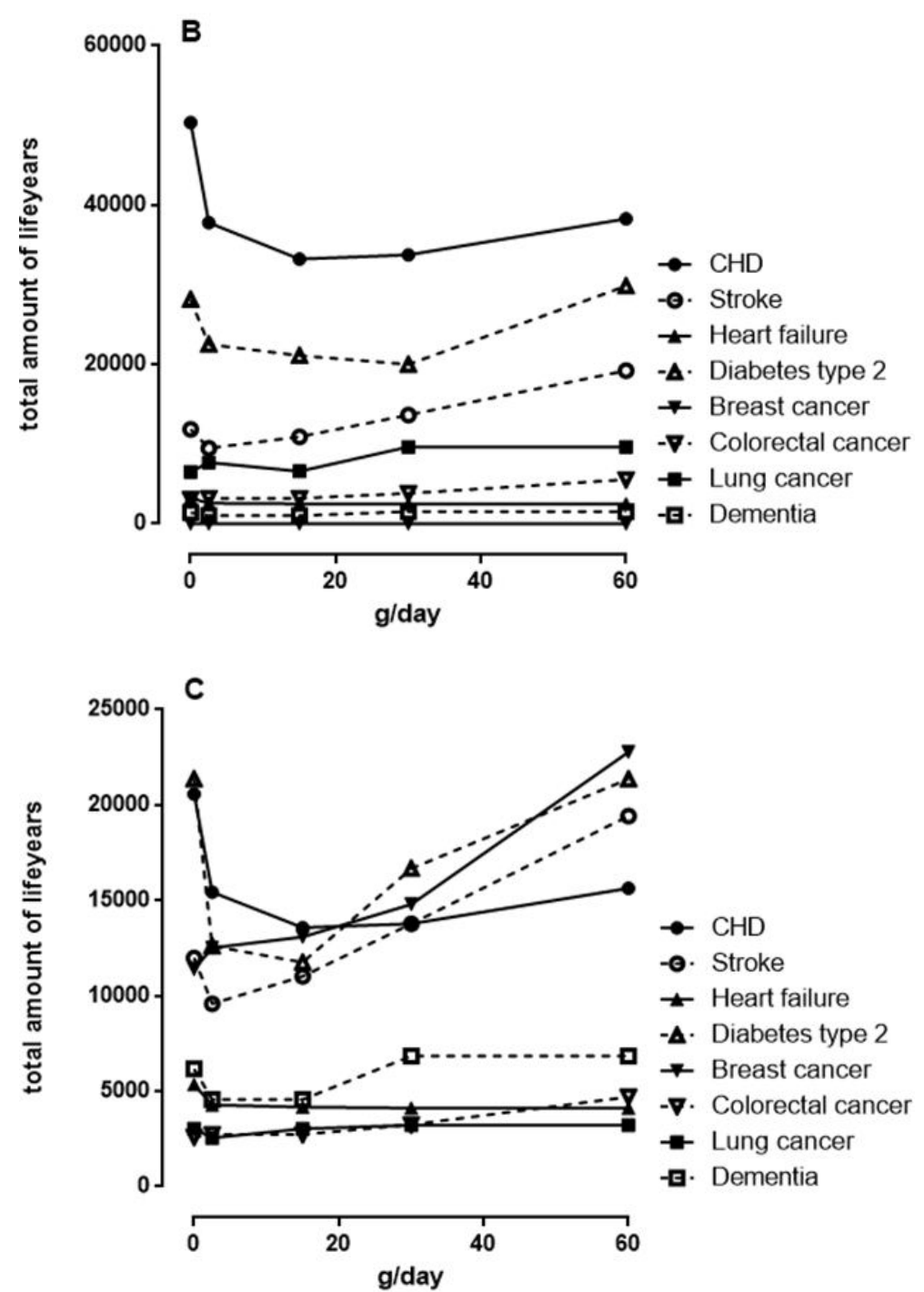

Alcohol consumption categories are: $0 \mathrm{~g} /$ day: 0-2.5; $2.5 \mathrm{~g} /$ day: $2.5-14.9 ; 15 \mathrm{~g} /$ day: 15 - 29.9; $30 \mathrm{~g} /$ day: 30-59.9; $60 \mathrm{~g}$ /day or higher: $\geq 60$. The lowest alcohol consumption level of each alcohol consumption category has been used on the $\mathrm{X}$-axis to indicate the alcohol consumption category. Risks were calculated for the whole population corrected for the gender ratio in the Dutch population.

Figure 2: Cumulative Disability Adjusted Life Years (DALY: total amount of life years) for the most burdensome diseases in the Netherlands per alcohol consumption category for men and women (A), relative risks for the most burdensome diseases in men (B) and relative risks for the most burdensome diseases in women $(\mathrm{C})$

\section{Discussion}

This paper estimated distributions of a theoretical relative risk, a disease incidence and a disease burden showing that alcohol consumption is associated with the sum of the Dutch eight most burdensome diseases in a J-shaped way. The results suggest that more moderate alcohol consumption, shown here in Figure 1 as between 2.5-29.9 g alcohol per day for both men and women, is related to the lowest relative risk, the lowest incidence and the lowest disease burden of these selected diseases for both Dutch men and women. These estimations equate to approximately 1.5 to 3 glasses daily which is higher than the current Dutch Health Council guideline of none or no more than one glass daily.

The relatively low relative risk at alcohol doses of 2.5-29.9 g alcohol/day is caused by a relatively low risk for coronary heart disease, stroke, heart failure, diabetes type 2 and dementia and a relatively high risk for breast cancer, lung cancer and colorectal cancer. The J-shape for this risk association corresponds to the J-shaped association generally described between alcohol consumption and all-cause or overall mortality [29-31].

When comparing men and women, men had a higher incidence of coronary heart disease, diabetes type 2, COPD and lung cancer, but in contrast had a lower incidence of heart failure, breast cancer and dementia. Overall, approximately 122,180 women were diagnosed with a disease in 2011, whereas 5\% fewer men were diagnosed. This gender distribution corresponds to the absolute number of deaths in 2011; a little over 70,000 women and a little over 65,000 men died in The Netherlands. 
The reason for choosing disease incidence rather than mortality is practical. Meta-analyses of the association between alcohol consumption and disease-specific mortality exist only for coronary heart disease and stroke [10]. Consequently, such an analysis would include a fraction of the total number of deaths occurring in that time frame. For example, of the 70,000 women and 65,000 men dying in 2011, only 9,000 men and 9,000 women died of coronary heart disease and stroke in 2011, approximately $13 \%$ of the total deaths in that year.

The approach of this paper estimates the relative risks, incidence and disease burden of a specific set of diseases and as such may not represent a tangible entity. These estimates were, however, constructed to evaluate the scientific basis for the Dutch dietary guidelines, that is, what is the optimal diet and more specifically, what is the optimal amount of alcohol consumption associated with the lowest burden of disease in The Netherlands. Such an approach necessarily requires, however, trade-offs among these conditions. For example, individuals who would like to avoid breast cancer risk beyond any other disease by optimizing their lifestyle should stop drinking alcohol to maximally reduce that risk, whereas individuals who have relative risk factors for cardiovascular disease such as familial hypercholesterolemia or hypertension could consider continuing to drink alcohol moderately, especially after menopause. However, there is a balance between positive and negative health effects on a population level. The choice for consuming alcohol in moderation or not is, therefore, always a personal consideration that reflects an individual's preferences and risk tolerance.

To our knowledge our methodical approach for estimating the cumulative relative risk is new and has not been applied before. The usual way of evaluating the impact of a specific life style factor in a population is by estimating DALYs (disability-adjusted life years) and/or QALYs (quality-adjusted life years). An estimate of DALYs has been provided as well and shows a very similar distribution over the various drinking categories.

This approach has various shortcomings. One of the shortcomings is that we did not correct for the occurrence of two diseases in one year (the year 2011). The chance of having two incidences at the same time is, however, considered to be small, but may still affect the risk reductions calculated [32]. Such a co-incidence may occur for metabolic diseases like coronary heart disease and diabetes mellitus type 2, and may be less likely for other combinations [33]. This may lead to an overestimation of the risk reduction, but will not affect the range of alcohol consumption that is associated with a lower risk for these diseases as such.

This simple addition of the various contributing relative risks, incidences and DALY's may not, however, provide a quantitatively correct number, because each disease may vary in its confounding factors. A full correction for all potential confounding factors was not performed. Such a correction would be scientifically interesting but was not feasible nor intended given the scope of the analysis.

Other shortcomings concern the general shortcomings in epidemiological research, such as disease misclassification, misreporting of alcohol consumption confounding and generalizability of the results to every age group, social class and ethnicity. One general potential shortcoming being discussed in relation to alcohol consumption concerns the 'sick quitters theory', which argues that people with a history of alcohol abuse or alcohol dependence and do not drink anymore, would be contributing to an increased risk of teetotalers [34]. All recent epidemiological studies, however, have excluded previous alcohol abusers and alcoholics. In addition, in the meta-analyses and other pooled analyses used for this overview the control drinking category was chosen as nondrinkers (without a history of alcohol abuse and alcohol dependence) and very light drinkers (0-2.5 g/ alcohol per day).

The Dutch Health Council has indicated that the difference in national alcohol guidelines most likely was caused by the different approach chosen, namely the intention to reduce the most burdensome diseases in The Netherlands. This approach is indeed different from those chosen by other countries as well as different from the approach used for the previous guideline. The analysis provided in this paper is based on the alternative approach chosen by the Dutch Health Council. We extended their analysis by making a cumulative estimate of the overall effect of moderate alcohol consumption on the diseases of interest. This analysis now suggests that the optimal alcohol consumption level is not at less than one glass a day, but rather in the range of drinking between 2.5 and $30 \mathrm{~g}$ of alcohol (less than one up to three glasses) per day.

Usually lower levels of alcohol consumption are advised than those that could be derived from epidemiological research. A lower level for advice is considered an extra safety margin. This was the case for the previously issued guidelines, based on the association between alcohol consumption and overall mortality [35-37]. Also, it would be irresponsible to promote alcohol consumption to lower the risk for specific diseases or for any health benefit. After all, alcohol consumption may lead into societal problems and into alcohol abuse and alcohol dependence. Having a healthy lifestyle including non-smoking, maintaining a healthy body weight, eating a balanced diet in moderation and being physically active, will significantly improve your health. Also, alcohol should not be consumed under specific circumstances, such as when becoming or being pregnant, when combined with activities such as driving and operating machinery, or when working. However, the present analysis shows that there appears to be no scientific basis to decrease alcohol guidelines further into: "Do not drink alcohol, or if any only drink one glass daily".

This paper suggests that moderate alcohol consumption of up to $30 \mathrm{~g}$ of alcohol per day is associated with the lowest risk for the most burdensome diseases in The Netherlands for both men and women [38-41]. 


\section{Acknowledgements}

This work was supported by the Foundation for Responsible Alcohol Consumption (Dutch acronym: STIVA). United in STIVA the Dutch producers and importers of beer, wine and spirits actively contribute to the promotion of responsible consumption of alcohol and reducing alcohol abuse.

The views expressed in this paper are those of the authors and do not necessarily reflect the opinion or policies of STIVA nor its members. The authors declare there is no conflict of interest.

\section{References}

1. Rehm J (2011) The risks associated with alcohol use and alcoholism. Alc Res Health 34:135-43.

2. Laramee P, Kusel J, Leonard S, Aubin HJ, Francois C, et al. (2013) The economic burden of alcohol dependence in Europe. Alcohol Alcohol 48:259-69.

3. Brown SA, McGue M, Maggs J, Schulenberg J, Hingson R, et al. (2008) A developmental perspective on alcohol and youths 16 to 20 years of age. Pediatrics 121 : S290-310.

4. Hendriks HFJ, Schrieks IC (2015) Adolescent alcohol consumption: brain health outcomes. J Child Adol Behav: 238.

5. Boffetta P, Garfinkel L (1990) Alcohol drinking and mortality among men enrolled in an American Cancer Society prospective study. Epidemiol 1: 342-8.

6. Mukamal KJ, Rimm EB (2008) Alcohol consumption: risks and benefits. Curr Ather Rep 10: 536-43.

7. Rimm EB, Klatsky A, Grobbee D, Stampfer MJ (1996) Review of moderate alcohol consumption and reduced risk of coronary heart disease: is the effect due to beer, wine, or spirits. BMJ 312:731-6.

8. Koppes LL, Dekker JM, Hendriks HF, Bouter LM, Heine RJ (2005) Moderate alcohol consumption lowers the risk of type 2 diabetes: a meta-analysis of prospective observational studies. Diab Care 28: 719-25.

9. Ruitenberg A, van Swieten JC, Witteman JC, Mehta KM, van Duijn CM, et al. (2002) Alcohol consumption and risk of dementia: the Rotterdam Study. Lancet 359: 281-6.

10. Ronksley PE, Brien SE, Turner BJ, Mukamal KJ, Ghali WA (2011) Association of alcohol consumption with selected cardiovascular disease outcomes: a systematic review and meta-analysis. BMJ 342: d671.

11. Harding R, Stockley CS (2007) Communicating through government agencies. Annals of Epidemiol 17: S98-102.

12. Kromhout D, Spaaij CJ, de Goede J, Weggemans RM (2016) The 2015 Dutch food-based dietary guidelines. Eur J Clin Nutr 70: 869-78.

13. Gezondheidsraad (2015) Richtlijnen goede voeding 2015. Den Haag: Gezondheidsraad 2015.

14. Gezondheidsraad (2006) Richtlijnen goede voeding 2006. Den Haag: Gezondheidsraad 2006.

15. Gezondheidsraad (2015) Werkwijze van de Commissie Richtlijnen goede voeding 2015.

16. van der Lucht F, Polder JJ (2010) Van gezond naar beter. Kernrapport van de Volksgezondheid Toekomst Verkenning. Bilthoven: RIVM $2010: 270061005$.

17. Gezondheidsraad (2015) Alcohol - Achtergronddocument bij Richtlijnen goede voeding 2015. Den Haag:Gezondheidsraad A15/05.

18. Gezondheidsraad (2015) Alcoholhoudende dranken - Achtergronddocument bij Richtlijnen goede voeding 2015. Den Haag:Gezondheidsraad A15/06.

19. van der Gaag MS, van Tol A, Vermunt SH, Scheek LM, Schaafsma G, et al. (2001) Alcohol consumption stimulates early steps in reverse cholesterol transport. J Lip Res 42: 2077-83.

20. van Tol A, Hendriks HF (2001) Moderate alcohol consumption: effects on lipids and cardiovascular disease risk. Curr Opin Lipidol 12: 19-23.

21. Beulens JW, Rimm EB, Hu FB, Hendriks HF, Mukamal KJ (2008) Alcohol consumption, mediating biomarkers, and risk of type 2 diabetes among middle-aged women. Diab Care 31: 2050-5.

22. Hendriks HF, Veenstra J, Velthuis-te Wierik EJ, Schaafsma G, Kluft C (1994) Effect of moderate dose of alcohol with evening meal on fibrinolytic factors. BMJ 308: 1003-6.

23. Joosten MM, Beulens JW, Kersten S, Hendriks HF (2008) Moderate alcohol consumption increases insulin sensitivity and ADIPOQ expression in postmenopausal women: a randomised, crossover trial. Diabetol 51: 1375-81.

24. Schrieks IC, van den Berg R, Sierksma A, Beulens JW, Vaes WH, et al. (2013) Effect of red wine consumption on biomarkers of oxidative stress. Alcohol Alcohol 48: 153-9.

25. Sierksma A, Patel H, Ouchi N, Kihara S, Funahashi T, et al. (2004) Effect of moderate alcohol consumption on adiponectin, tumor necrosis factor- $\alpha$, and insulin sensitivity. Diab Care 27: 184-9.

26.Volksgezondheidenzorg.info (2017) Ranglijst aandoeningen op basis van incidentie, Bilthoven, Netherlands.

27. Volksgezondheidenzorg (2017) Stemmingsstoornissen, Bilthoven, Netherlands.

28. Volksgezondheidenzorg (2017) Ziektelast in DALY's, Bilthoven, Netherlands.

29. Costanzo S, Di Castelnuovo A, Donati MB, Iacoviello L, de Gaetano G (2010) Cardiovascular and overall mortality risk in relation to alcohol consumption in patients with cardiovascular disease. Circulation 121: 1951-9.

30. Ford ES, Zhao G, Tsai J, Li C (2011) Low-risk lifestyle behaviors and all-cause mortality: findings from the National Health and Nutrition Examination Survey III Mortality Study. Am J Pub Health 101: 1922-9.

31. Smyth A, Teo KK, Rangarajan S, O’Donnell M, Zhang X, et al. (2015) Alcohol consumption and cardiovascular disease, cancer, injury, admission to hospital, and mortality: a prospective cohort study. Lancet 386:1945-54

32. Jewell NP (2003) Statistics for Epidemiology. Chapman and Hall/CRC, Boca Raton London New York Washington DC.

33. Koppes LL, Dekker JM, Hendriks HF, Bouter LM, Heine RJ (2006) Meta-analysis of the relationship between alcohol consumption and coronary heart disease and mortality in type 2 diabetic patients. Diabetol 49: 648-52.

34. Stockwell T, Zhao J, Panwar S, Roemer A, Naimi T, et al. (2016) Do "Moderate" Drinkers Have Reduced Mortality Risk? A Systematic Review and Meta-Analysis of Alcohol Consumption and All-Cause Mortality. JSAD 77: 185-98. 
35. Ferrari P, Licaj I, Muller DC, Kragh Andersen P, Johansson M, et al. (2014) Lifetime alcohol use and overall and cause-specific mortality in the European Prospective Investigation into Cancer and nutrition (EPIC) study. BMJ 4: e005245.

36. Di Castelnuovo A, Costanzo S, Bagnardi V, Donati MB, Iacoviello L, et al. (2006) Alcohol dosing and total mortality in men and women: an updated metaanalysis of 34 prospective studies. Arch Int Med 66:2437-45.

37. Jayasekara H, English DR, Room R, MacInnis RJ (2014) Alcohol consumption over time and risk of death: a systematic review and meta-analysis. Am J Epidemiol 179: 1049-59.

38. Padilla H, Gaziano MJ, Djousse L (2010) Alcohol consumption and risk of heart failure: a meta-analysis. Phys Sports Med 38: 84-9.

39. Tjonneland A, Christensen J, Olsen A, Stripp C, Thomsen BL, et al. (2007) Alcohol intake and breast cancer risk: the European Prospective Investigation into Cancer and Nutrition (EPIC). Cancer Causes Control 18: 361-73.

40. Freudenheim JL, Ritz J, Smith-Warner SA, Albanes D, Bandera EV, et al. (2005) Alcohol consumption and risk of lung cancer: a pooled analysis of cohort studies. Am J Clin Nutr 82: 657-67.

41. Anstey KJ, Mack HA, Cherbuin N (2009) Alcohol consumption as a risk factor for dementia and cognitive decline: meta-analysis of prospective studies. Am J Geriatr Psych 17: 542-55. 